\title{
Non-Equilibrium Lattice Fluid Modeling of Gas Sorption for
}

\section{Fluorinated Poly(Ether Imide)s - Supporting Information}

Albert X. Wu ${ }^{1}$, James A. Drayton ${ }^{1}$, Xinyi Ren ${ }^{2}$, Katherine Mizrahi Rodriguez ${ }^{3}$, Aristotle F. Grosz ${ }^{1}$, Ji-Woong Lee ${ }^{2}$, and Zachary P. Smith ${ }^{1 *}$

*Corresponding author: zpsmith@mit.edu

${ }^{1}$ Department of Chemical Engineering, Massachusetts Institute of Technology, Cambridge, MA 02139, USA

${ }^{2}$ Department of Chemistry, University of Copenhagen, Universitetsparken 5, Ø 2100 Copenhagen, Denmark

${ }^{3}$ Department of Materials Science and Engineering, Massachusetts Institute of Technology, Cambridge, MA 02139, USA 
Table S1: LFPs for gases and polymers.

\begin{tabular}{|c|c|c|c|c|}
\hline Gases & $T^{*}(\mathrm{~K})$ & $p^{*}(\mathrm{MPa})$ & $\rho^{*}\left(\mathrm{~g} \mathrm{~cm}^{-3}\right)$ & Ref. \\
\hline $\mathrm{N}_{2}$ & 145 & 160 & 0.943 & 1 \\
\hline $\mathrm{O}_{2}$ & 170 & 280 & 1.29 & 1 \\
\hline $\mathrm{CH}_{4}$ & 215 & 250 & 0.5 & 1 \\
\hline $\mathrm{CO}_{2}$ & 300 & 630 & 1.515 & 1 \\
\hline Polymers & $T^{*}(\mathrm{~K})$ & $p^{*}(\mathrm{MPa})$ & $\rho^{*}\left(\mathrm{~g} \mathrm{~cm}^{-3}\right)$ & Ref. \\
\hline Poly(PFMD) & $640 \pm 3.62$ & $300 \pm 28$ & $2.184 \pm 0.006$ & 2 \\
\hline Poly(PFMMD) & $616 \pm 18$ & $250 \pm 23$ & $2.200 \pm 0.010$ & 2 \\
\hline Teflon AF 2400 & 624 & 250 & 2.13 & 3 \\
\hline Teflon AF 1600 & 575 & 280 & 2.16 & 3 \\
\hline Hyflon AD 80 & 550 & 180 & 2.150 & 4 \\
\hline 6FDA-ODA & 804.2 & 526.8 & 1.658 & 5 \\
\hline 6FDA-6FpDA & 750.1 & 476.5 & 1.806 & 5 \\
\hline 6FDA-HAB & $720 \pm 41$ & $481 \pm 20$ & $1.609 \pm 0.039$ & 6 \\
\hline TR450-30min & $930.0 \pm 23$ & $446.9 \pm 7.3$ & $1.528 \pm 0.037$ & 6 \\
\hline
\end{tabular}


1. Methods:

a. Materials:

The perfluorinated dianhydride monomer, 1,4-bis(3,4dicarboxytrifluorophenoxy)tetrafluorobenzene (10FEDA), was synthesized using the procedure described below. Tetrafluorohydroquinone (TFHQ, TCI America, Portland, OR, USA) was purified via vacuum sublimation at $160{ }^{\circ} \mathrm{C}$ and tetrafluorophthalonitrile (TFPN, TCI America, Portland, OR, USA) was used as received. The hydrogen dianhydride monomer, 1,4-bis(3,4dicarboxyphenoxy)benzene dianhydride (10HEDA), was purchased from Marshallton Research Laboratories Inc. (King, NC, USA) and used as received. The hydrogen diamine, mphenylenediamine (MPD, MilliporeSigma, St. Louis, MO, USA) was purified via recrystallization (2 g / $4 \mathrm{~mL} \mathrm{H}_{2} \mathrm{O}$ at $25^{\circ} \mathrm{C}$ ) and the fluorinated diamine, 2,3,5,6-tetrafluoro-1,4-phenylenediamine (TFMPD, TCI America, Portland, OR, USA), was purified via vacuum sublimation at $130{ }^{\circ} \mathrm{C}$. Dimethylformamide (DMF, MilliporeSigma, St. Louis, MO, USA), triethylamine (Et $3 \mathrm{~N}$, MilliporeSigma, St. Louis, MO, USA), 2.0 M hydrochloric acid (HCl, MilliporeSigma, St. Louis, MO, USA), toluene (MilliporeSigma, St. Louis, MO, USA), sulfuric acid $\left(\mathrm{H}_{2} \mathrm{SO}_{4}, 99.99 \%\right.$, MilliporeSigma, St. Louis, MO, USA), xylenes (MilliporeSigma, St. Louis, MO, USA), acetic anhydride (AcAn, MilliporeSigma, St. Louis, MO, USA), petroleum ether (MilliporeSigma, St. Louis, MO, USA), and dimethylacetamide (DMAc, MilliporeSigma, St. Louis, MO, USA) were used as received. Oxygen, nitrogen, methane, and carbon dioxide gases (UHP purity, Airgas, Radnor, PA, USA) were used as received.

b. 10FEDA Monomer Synthesis:

The 10FEDA monomer synthesis consists of three steps adapted from Ando et al..$^{7-9}$, summarized in Figure $\mathrm{S} 1$ below. The bisphthalonitrile precursor (10FEDP) is first formed by the aromatic 
nucleophilic substitution of TFHQ and TFPN in base. Next, 10FEDP is hydrolyzed to form a tetracarboxylate in step 2, which is finally dehydrated into the 10FEDA dianhydride in step 3.

1.<smiles>Oc1c(F)c(F)c(O)c(F)c1F</smiles>

TFHQ<smiles>N#Cc1c(F)c(F)c(F)c(F)c1C#N</smiles>

TFPN
$\underset{\mathrm{DMF}}{\stackrel{\mathrm{Et}_{3} \mathrm{~N}}{\longrightarrow}}$<smiles>CC(C)(C)[C@@H](OS(=O)(=O)O)C(=O)O</smiles><smiles>N#Cc1c(F)c(F)c(Oc2c(F)c(F)c(Oc3c(F)c(F)c(C#N)c(C#N)c3F)c(F)c2F)c(F)c1C#N</smiles>

10FEDP
10FEDP-COOH

2.<smiles>N#Cc1c(F)c(F)c(Oc2c(F)c(F)c(Oc3c(F)c(F)c(C#N)c(C#N)c3F)c(F)c2F)c(F)c1C#N</smiles>

3.<smiles>C[C@H](C(=O)O)C(C)(C)C</smiles><smiles>O=C1OC(=O)c2c(F)c(Oc3c(F)c(F)c(Oc4c(F)c(F)c5c(c4F)C(=O)OC5=O)c(F)c3F)c(F)c(F)c21</smiles>

10FEDA

Figure S1: Synthetic pathway to synthesize 10FEDA from TFHQ and TFPN.

10FEDP Synthesis. $1.82 \mathrm{~g}$ of TFHQ (10 mmol), $8.0 \mathrm{~g}$ of TFPN $(40 \mathrm{mmol})$, and $40 \mathrm{~mL}$ of DMF were added into a $100 \mathrm{~mL}$ round bottom flask with a magnetic stir bar. The mixture was stirred until all solids were dissolved and the flask was immersed in an ice bath. The ice bath was found to improve yield. A syringe pump was set up to add $2.8 \mathrm{~mL}$ of Et $3 \mathrm{~N}(20 \mathrm{mmol})$ dropwise into the solution over 20 minutes $(0.14 \mathrm{~mL} / \mathrm{min})$. The reaction solution was then stirred for 10 more minutes on ice (30 minutes total), the ice bath was removed and the reaction was stirred at room temperature for an additional 1.5 hours. The solution was poured into a $0.4 \mathrm{M} \mathrm{HCl}$ solution (200 $\mathrm{mL}$ ) in an Erlenmeyer flask, resulting in a cloudy, white solution and an oily precipitate. The white 
solution was decanted and the oily precipitate was washed twice with deionized water. The precipitate was left to dry in the flask overnight at $60{ }^{\circ} \mathrm{C}$, resulting in off-white crystals. Assynthesized 10FEDP was purified in the same flask via recrystallization in toluene by heating to

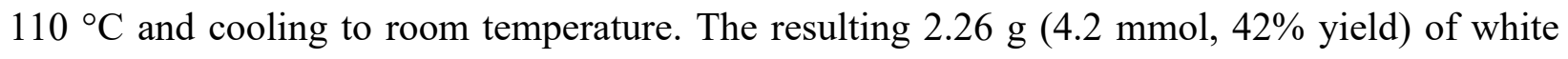
powder was collected via vacuum filtration and dried in the oven overnight at $60^{\circ} \mathrm{C}$.

10FEDP Hydrolysis to 10FEDP-COOH. $2.26 \mathrm{~g}$ of $10 \mathrm{FEDP}$ and $40 \mathrm{~mL}$ of $60 \% / 40 \%$ $\mathrm{H}_{2} \mathrm{SO}_{4} /$ deionized water was added into a $100 \mathrm{~mL}$ round bottom flask with a magnetic stir bar. The flask was connected to a water condenser, placed in an oil bath, and heated to $200{ }^{\circ} \mathrm{C}$. An initial stir rate of approximately $900 \mathrm{rpm}$ was required to initiate good mixing of the solids in the liquid, then the stirring rate was reduced to $300 \mathrm{rpm}$. After 4 hours, the mixture was cooled to room temperature and deionized water was slowly added into the reaction solution to induce precipitation of the product. A gray-white product $(2.11 \mathrm{~g}, 3.4 \mathrm{mmol}, 82 \%$ yield) was collected via vacuum filtration using a glass microfiber fiber paper (Cytiva Whatman GF/C, Marlborough, MA) washed with deionized water, and dried in the oven overnight at $60{ }^{\circ} \mathrm{C}$.

Dehydration of 10FEDP-COOH to 10FEDA. $2.11 \mathrm{~g}$ of 10FEDP-COOH, $20 \mathrm{~mL}$ of xylenes, and $3.2 \mathrm{~mL}$ of AcAn (34 mmol) were added with a magnetic stir bar to a $50 \mathrm{~mL}$ round bottom flask. The flask was connected to a water condenser, placed in an oil bath, heated at $130{ }^{\circ} \mathrm{C}$ and stirred at $300 \mathrm{rpm}$ for 2 hours, and then cooled to room temperature. Petroleum ether was slowly added to the reaction solution to induce precipitation of the final product. The white powder product (1.82 g, $3.1 \mathrm{mmol}, 92 \%$ yield) was collected via vacuum filtration, dried under full vacuum at $60{ }^{\circ} \mathrm{C}$, and stored under vacuum. The overall yield of 10FEDA was $31 \%$ with respect to the starting reagents. 


\section{c. Polymer Synthesis and Casting:}

The poly(ether imides) were synthesized through a two-step procedure. In the first step to create the poly(amic acid), the center joint of a $100 \mathrm{~mL}$ three-neck round bottom flask was attached to a Schlenk line. A magnetic stir bar was put inside and the joints were sealed using rubber septa. The flask was evacuated to full vacuum and filled with flowing $\mathrm{N}_{2}$, cycled three more times, and left under flowing $\mathrm{N}_{2}$ for the remainder of the synthesis. For the two 10FEDA-based polymers, equimolar amounts of dianhydride $(3 \mathrm{mmol})$ and diamine $(3 \mathrm{mmol})$ were separately dissolved in $5.5 \mathrm{~mL}$ of DMAc each. The diamine solution was injected into the flask through the rubber septum, followed by the dianhydride solution to make a $20 \% \mathrm{w} / \mathrm{v}$ solution ( $11 \mathrm{~mL}$ total volume). The flask was then covered with aluminum foil to prevent potential MPD monomer decomposition and left to stir for 3 days at room temperature. For the two 10HEDA-based polymers, 3 mmol of 10HEDA was dissolved in $15 \mathrm{~mL}$ of DMAc by stirring at $80^{\circ} \mathrm{C}$ overnight. An equimolar amount of diamine ( $3 \mathrm{mmol}$ ) was separately dissolved in $4 \mathrm{~mL}$ DMAc. The two solutions were mixed following the same procedure as above, resulting in a $9.3 \% \mathrm{w} / \mathrm{v}$ solution. The 10 HEDA-TFMPD polymerization was performed at $80{ }^{\circ} \mathrm{C}$ to encourage higher molecular weight. All other syntheses were performed at room temperature.

A procedure inspired by Hougham et al. ${ }^{10}$ was modified for film casting and imidization, as described in detail in our previous study. ${ }^{11}$ For this study, one additional modification was made to use DMAc as the casting solvent. After placing the petri dish inside the vacuum oven, a $16 \mathrm{~h}$ dynamic vacuum was applied $(25 \mathrm{inHg})$ to the casting solution for slow removal of solvent at room temperature. The same tube furnace curing procedure reported previously was used to imidize the film ${ }^{11}$, resulting in poly(ether imide) films of approximately $30 \mu \mathrm{m}$ thickness. 
d. Characterization Methods:

The chemical structure of 10FEDA and its intermediates was verified via ${ }^{19} \mathrm{~F}$ nuclear magnetic resonance (NMR) in DMSO-d6 (Cambridge Isotope Laboratories, Tewksbury, MA, USA) on a $400 \mathrm{MHz}$ Bruker instrument and Fourier-transform infrared spectroscopy (FT-IR). The four poly(ether imides) were characterized using differential scanning calorimetry (DSC), gel permeation chromatography (GPC) and density. These methods are described in detail in a previous study. ${ }^{11}$

e. Pure-gas Sorption Measurements:

Pure-gas sorption characterization tests were performed on the poly(ether imides) for $\mathrm{N}_{2}, \mathrm{O}_{2}, \mathrm{CH}_{4}$, and $\mathrm{CO}_{2}$. Sorption isotherms up to 40 atm were collected at $35^{\circ} \mathrm{C}, 45^{\circ} \mathrm{C}, 55^{\circ} \mathrm{C}$, and $65^{\circ} \mathrm{C}$. The sample preparation and operating procedures for these tests have been described in detail previously. ${ }^{12}$ The pressure-decay automated system used for sorption tests (model 2200-X) was purchased from Maxwell Robotics. 
2. Synthesis and Characterization Results:

a. Monomer Synthesis and Characterization

The chemical structure of the 10FEDA monomer synthesized for this study was confirmed using ${ }^{19} \mathrm{~F}$ NMR and FT-IR spectroscopy. Notably, the ${ }^{19} \mathrm{~F}$ peaks for 10FEDP, 10FEDP-COOH, and 10FEDA were previously catalogued by Ando et al. ${ }^{13}$ The ${ }^{19} \mathrm{~F}$ NMR for the three molecules are shown in Figure S2a with the corresponding peak assignments. All molecules showed a relative peak integration of 1:1:1:2 for peaks 1-3 compared to peak 4, as expected from the structure. In the ${ }^{19} \mathrm{~F}$ NMR for 10FEDA, small peaks associated with 10FEDP-COOH with a relative integration of 1:0.05 10FEDA:10FEDA-COOH are present. We suspect that due to the hygroscopic nature of the DMSO-d6 NMR solvent, the presence of water in the solvent may have caused a small amount of ring-opening to occur during the sample preparation process. However, the FT-IR spectrum for 10FEDA in Figure $\mathrm{S} 2 \mathrm{~b}$ does not show a broad -OH peak, suggesting full conversion to ring closure was achieved during the dehydration reaction step.

The FT-IR spectra for the three molecules are shown in Figure S2b with identifying functional groups highlighted. For 10FEDP, a characteristic nitrile peak was observed at $2250 \mathrm{~cm}^{-1}$. After hydrolysis to 10FEDP-COOH, that peak was replaced with a broad-OH peak at $3200 \mathrm{~cm}^{-1}$. Lastly, after dehydration to 10FEDA, the -OH peak was eliminated and characteristic dianhydride peaks at $1780 \mathrm{~cm}^{-1}$ and $1870 \mathrm{~cm}^{-1}$ were observed, confirming closure of the dianhydride ring. 

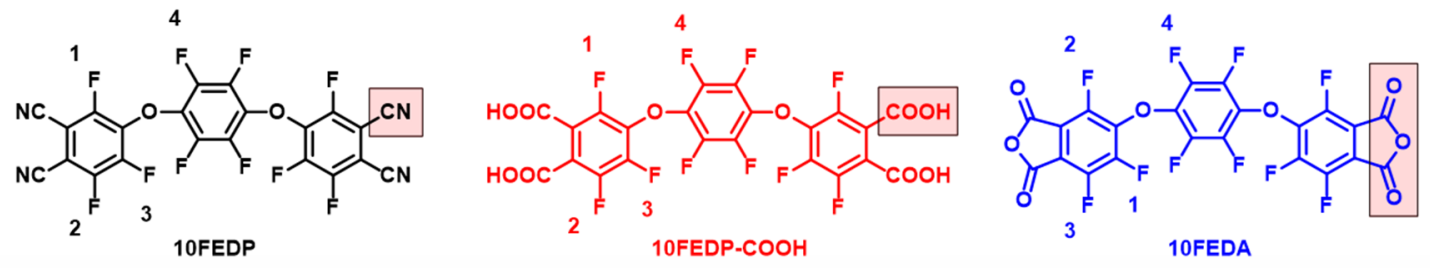

(a)

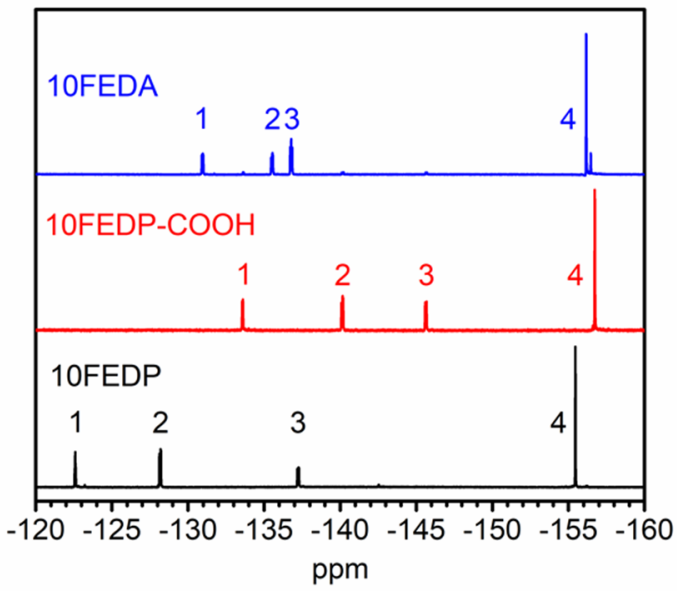

(b)

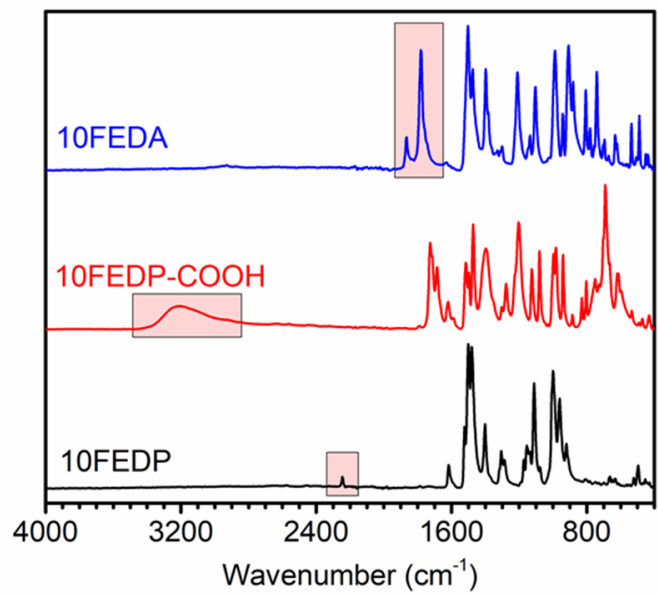

Figure S2: Monomer characterization for 10FEDP, 10FEDP-COOH, and 10FEDA using (a) ${ }^{19} \mathrm{~F}$ NMR and (b) FT-IR.

\section{b. Polymer Synthesis and Characterization}

Using the synthesized 10FEDA monomer, the four polymers shown in Figure 1 were synthesized and cast into films. As noted in previous reports, the as-cast films that were cast at $350{ }^{\circ} \mathrm{C}$ are not soluble in common solvents. ${ }^{9}$ Therefore, the GPC of only the poly(amic acid) precursor solution is reported in Table S2, showing a limited degree of polymerization prior to the high-temperature cure. The high-temperature cure procedure proposed by Hougham et al. suggests that simultaneous end-to-end chain extension and imidization reactions occur for these oligomeric chains, resulting in a film suitable for testing. ${ }^{10}$ Pictures of the polymer films are shown in Figure S3a. The functional groups present in the film can be verified via FT-IR, as shown in Figure S3b. Specifically, the peaks at 1780 and $1720 \mathrm{~cm}^{-1}$ are associated with imide stretching and the peak at $1380 \mathrm{~cm}^{-1}$ is associated with $\mathrm{C}-\mathrm{N}$ imide stretching, confirming successful imidization. ${ }^{11,14}$ The 
lack of amide and carboxylic acid peaks indicate that, at least within the resolution of FT-IR, crosslinking did not occur. Thus, the decreased solubility is attributed to increased aggregation of the polymer chains when curing above their $\mathrm{T}_{\mathrm{g}}$ since in the rubbery state, the polymer chains are able to preferentially rearrange prior to cooling below their $\mathrm{T}_{\mathrm{g}}{ }^{9}$ Additionally, the spectra for 10FEDA-TFMPD matches that in previous reports. ${ }^{9}$

(a)

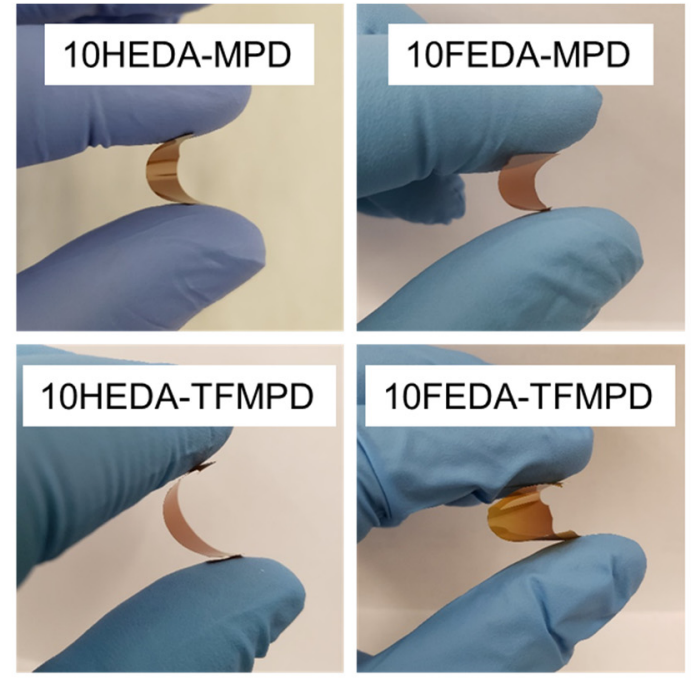

(b)

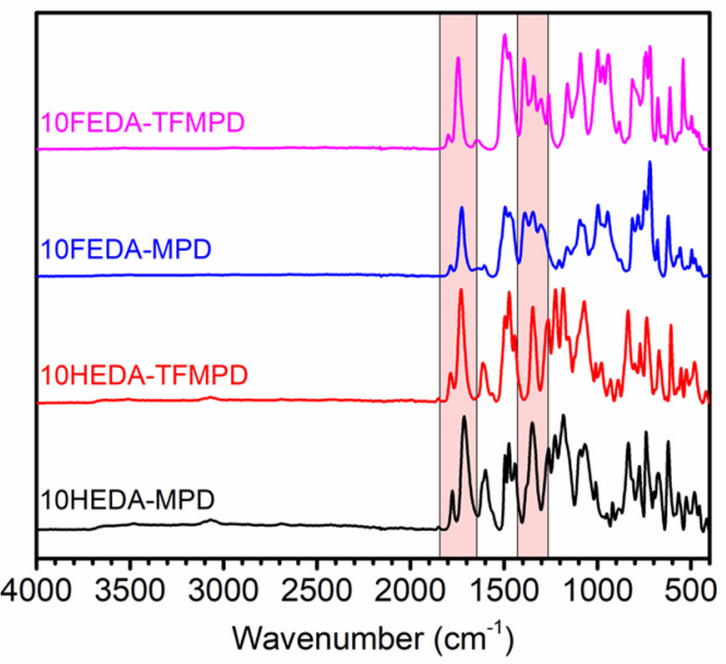

Figure S3: (a) Images of the four polymers after casting, resulting in robust films. (b) FTIR spectra for the four polymer films. 
Table S2: GPC of poly(amic acid)s.

\begin{tabular}{|l|l|l|l|}
\hline Polymer & $\mathrm{M}_{\mathrm{n}}\left(\mathrm{g} \mathrm{mol}^{-1}\right)$ & $\left.\mathrm{M}_{\mathrm{w}}(\mathrm{g} \mathrm{mol})^{-1}\right)$ & Degree of Polym. \\
\hline 10HEDA-MPD & 3,900 & 4,800 & 8 \\
\hline 10HEDA-TFMPD & 5,500 & 6,500 & 10 \\
\hline 10FEDA-MPD & 3,500 & 4,500 & 5 \\
\hline 10FEDA-TFMPD & 5,300 & 6,200 & 7 \\
\hline
\end{tabular}

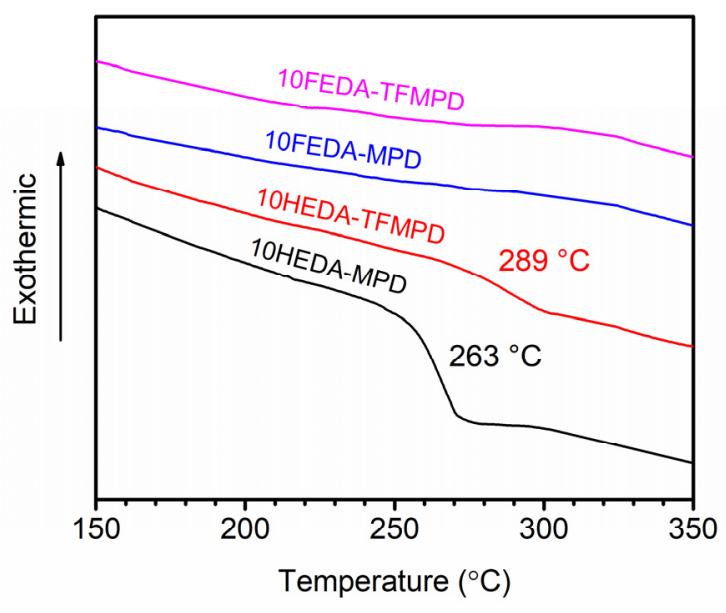

Figure S4: DSC traces for the four polymers with a $100^{\circ} \mathrm{C} / \mathrm{min}$ ramp rate. The third trace is shown here. Traces are offset for ease of viewing. 


\section{Sorption Characterization and NELF Modeling Results}

Table S3: $S_{\infty}$ values for 10HEDA-MPD in $\mathrm{cm}^{3}(\mathrm{STP}) \mathrm{cm}^{-3} \mathrm{~atm}^{-1}$.

\begin{tabular}{|l|l|l|l|l|}
\hline & $\mathrm{O}_{2}$ & $\mathrm{~N}_{2}$ & $\mathrm{CH}_{4}$ & $\mathrm{CO}_{2}$ \\
\hline $35^{\circ} \mathrm{C}$ & $0.130 \pm 0.007$ & $0.22 \pm 0.01$ & $0.73 \pm 0.04$ & $7.9 \pm 0.2$ \\
\hline $45^{\circ} \mathrm{C}$ & $0.111 \pm 0.006$ & $0.190 \pm 0.009$ & $0.58 \pm 0.03$ & $6.3 \pm 0.1$ \\
\hline $55^{\circ} \mathrm{C}$ & $0.096 \pm 0.005$ & $0.154 \pm 0.008$ & $0.50 \pm 0.03$ & $5.4 \pm 0.1$ \\
\hline $65^{\circ} \mathrm{C}$ & $0.090 \pm 0.005$ & $0.146 \pm 0.007$ & $0.43 \pm 0.02$ & $3.6 \pm 0.1$ \\
\hline
\end{tabular}

Table S4: $S_{\infty}$ values for 10HEDA-TFMPD in $\mathrm{cm}^{3}(\mathrm{STP}) \mathrm{cm}^{-3} \mathrm{~atm}^{-1}$.

\begin{tabular}{|l|l|l|l|l|}
\hline & $\mathrm{O}_{2}$ & $\mathrm{~N}_{2}$ & $\mathrm{CH}_{4}$ & $\mathrm{CO}_{2}$ \\
\hline $35^{\circ} \mathrm{C}$ & $0.44 \pm 0.02$ & $0.60 \pm 0.03$ & $2.4 \pm 0.1$ & $25.2 \pm 0.5$ \\
\hline $45^{\circ} \mathrm{C}$ & $0.33 \pm 0.02$ & $0.48 \pm 0.02$ & $1.71 \pm 0.09$ & $16.2 \pm 0.3$ \\
\hline $55^{\circ} \mathrm{C}$ & $0.25 \pm 0.01$ & $0.38 \pm 0.02$ & $1.24 \pm 0.06$ & $10.0 \pm 0.2$ \\
\hline $65^{\circ} \mathrm{C}$ & $0.23 \pm 0.01$ & $0.30 \pm 0.01$ & $0.94 \pm 0.05$ & $7.3 \pm 0.2$ \\
\hline
\end{tabular}

Table S5: $S_{\infty}$ values for 10FEDA-MPD in $\mathrm{cm}^{3}(\mathrm{STP}) \mathrm{cm}^{-3} \mathrm{~atm}^{-1}$.

\begin{tabular}{|l|l|l|l|l|}
\hline & $\mathrm{O}_{2}$ & $\mathrm{~N}_{2}$ & $\mathrm{CH}_{4}$ & $\mathrm{CO}_{2}$ \\
\hline $35^{\circ} \mathrm{C}$ & $0.89 \pm 0.04$ & $1.09 \pm 0.05$ & $3.0 \pm 0.1$ & $37.4 \pm 0.7$ \\
\hline $45^{\circ} \mathrm{C}$ & $0.64 \pm 0.03$ & $0.87 \pm 0.04$ & $2.5 \pm 0.1$ & $24.0 \pm 0.5$ \\
\hline $55^{\circ} \mathrm{C}$ & $0.57 \pm 0.03$ & $0.70 \pm 0.04$ & $1.9 \pm 0.1$ & $16.7 \pm 0.3$ \\
\hline $65^{\circ} \mathrm{C}$ & $0.45 \pm 0.02$ & $0.59 \pm 0.03$ & $1.51 \pm 0.08$ & $11.9 \pm 0.2$ \\
\hline
\end{tabular}


Table S6: $S_{\infty}$ values for 10FEDA-TFMPD in $\mathrm{cm}^{3}(\mathrm{STP}) \mathrm{cm}^{-3} \mathrm{~atm}^{-1}$.

\begin{tabular}{|l|l|l|l|l|}
\hline & $\mathrm{O}_{2}$ & $\mathrm{~N}_{2}$ & $\mathrm{CH}_{4}$ & $\mathrm{CO}_{2}$ \\
\hline $35^{\circ} \mathrm{C}$ & $1.06 \pm 0.05$ & $1.29 \pm 0.06$ & $3.5 \pm 0.2$ & $34.9 \pm 0.7$ \\
\hline $45^{\circ} \mathrm{C}$ & $0.83 \pm 0.04$ & $0.99 \pm 0.05$ & $2.6 \pm 0.1$ & $24.0 \pm 0.5$ \\
\hline $55^{\circ} \mathrm{C}$ & $0.65 \pm 0.03$ & $0.80 \pm 0.04$ & $2.1 \pm 0.1$ & $16.6 \pm 0.3$ \\
\hline $65^{\circ} \mathrm{C}$ & $0.52 \pm 0.03$ & $0.64 \pm 0.03$ & $1.78 \pm 0.09$ & $11.3 \pm 0.2$ \\
\hline
\end{tabular}

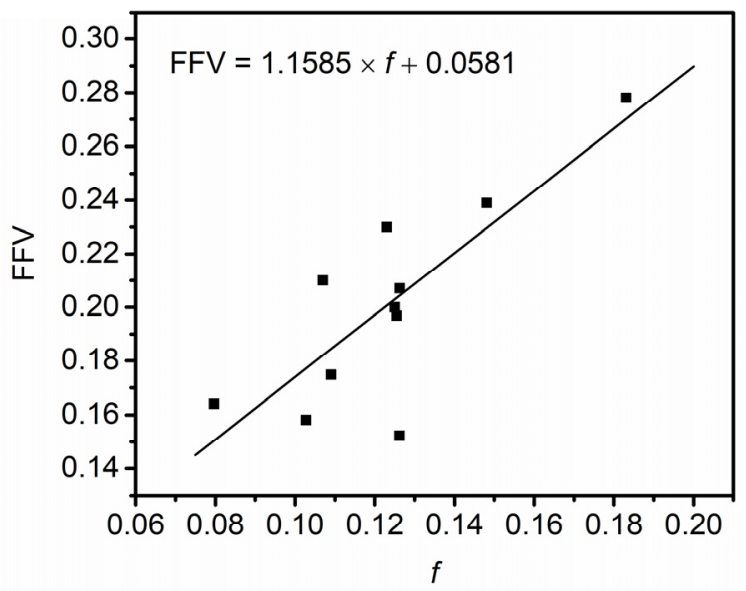

Figure S5: FFV vs $f$ plot. The polymers included here are Teflon AF $2400^{3}$, Teflon AF $1600^{3}$,

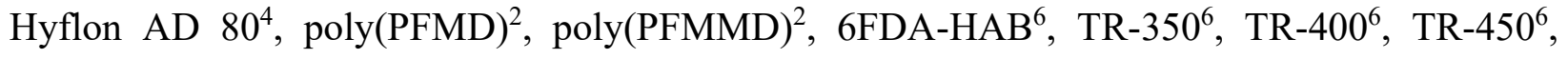
6FDA-ODA ${ }^{5}$, and 6FDA-6FpDA ${ }^{5}$. FFV for these polymers was calculated using our updated group contribution method. ${ }^{15}$ 

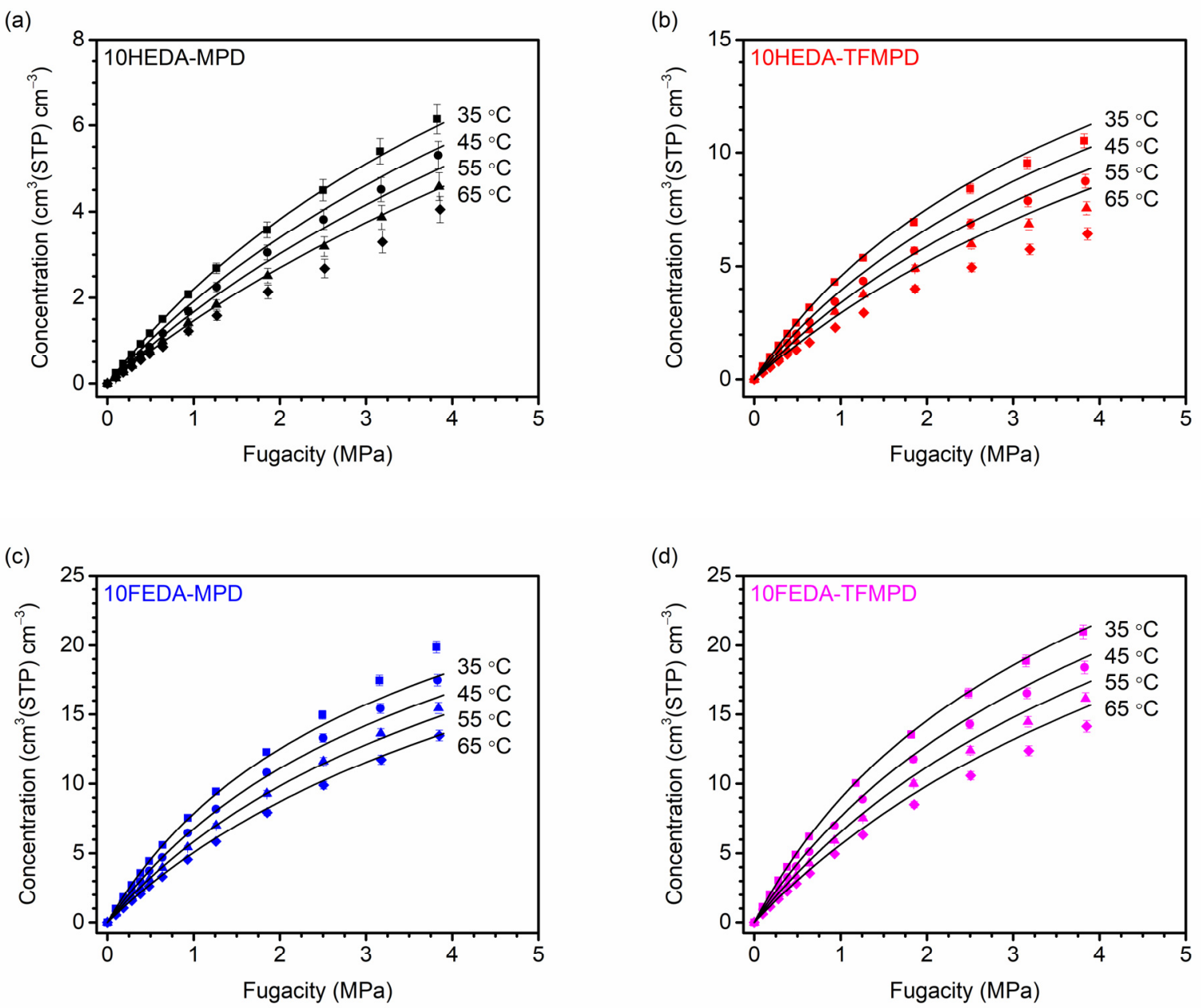

Figure S6: Isotherms for $\mathrm{O}_{2}$ for the four polymers at $35{ }^{\circ} \mathrm{C}$ (squares), $45{ }^{\circ} \mathrm{C}$ (circles), $55{ }^{\circ} \mathrm{C}$ (triangles), and $65^{\circ} \mathrm{C}$ (diamonds). 
(a)
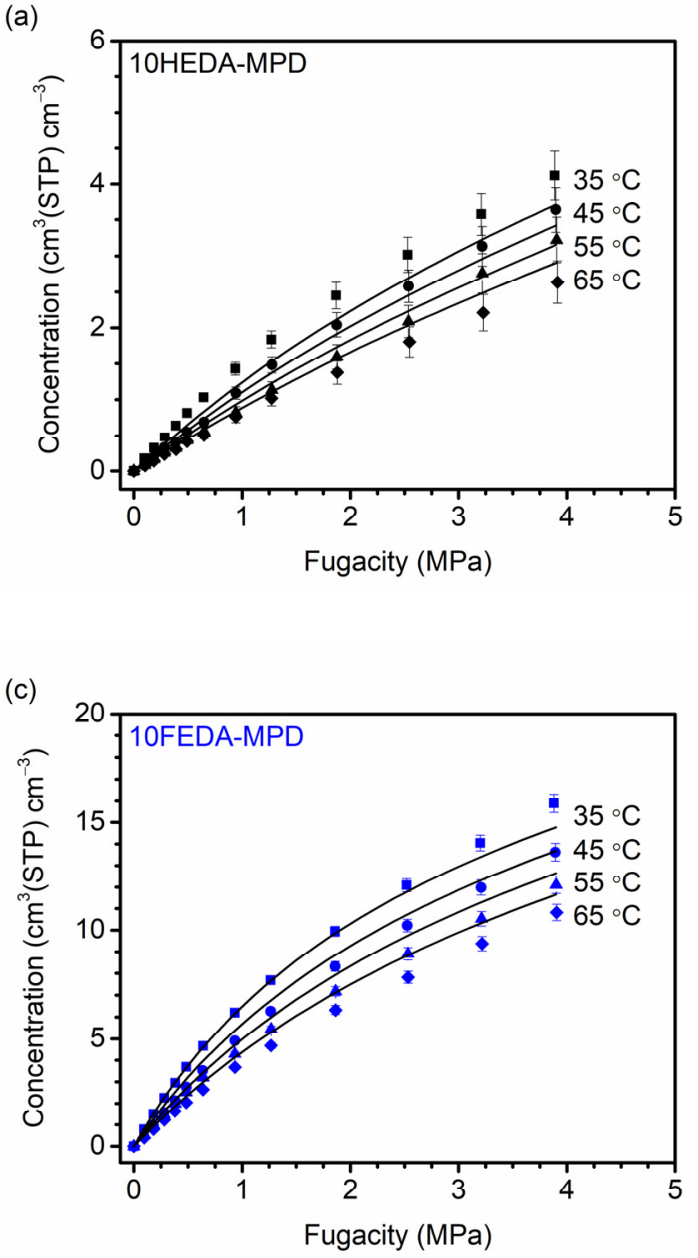
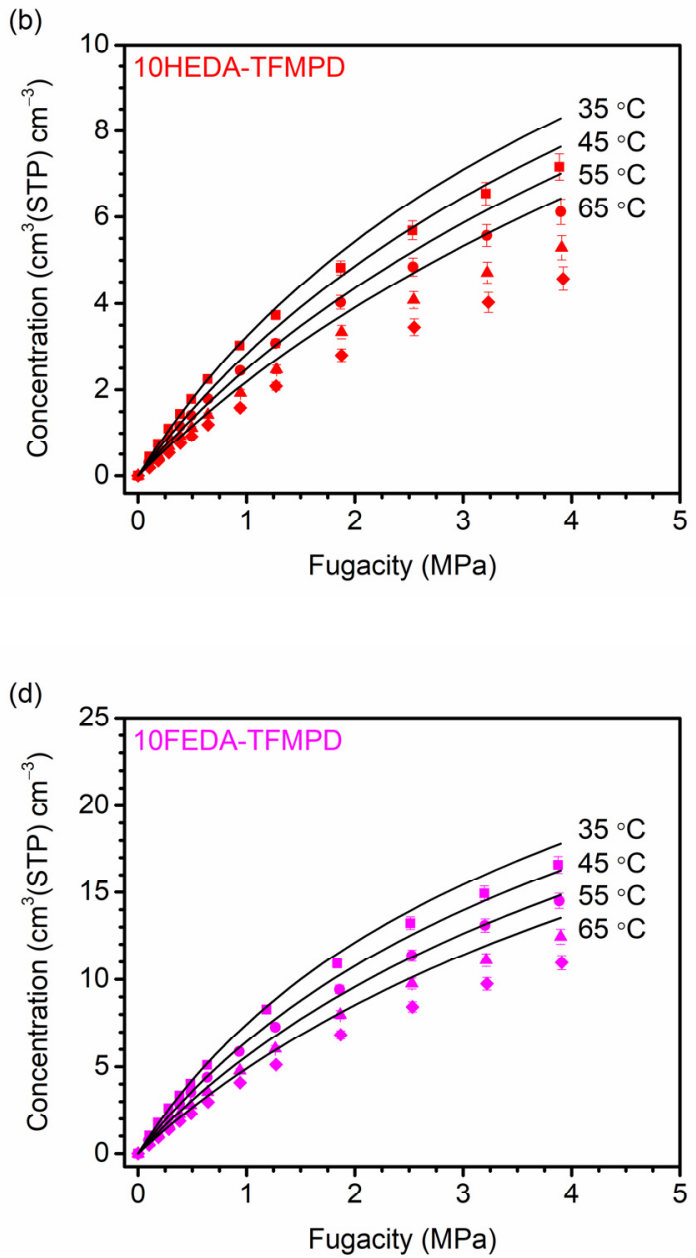

Figure S7: Isotherms for $\mathrm{N}_{2}$ for the four polymers at $35{ }^{\circ} \mathrm{C}$ (squares), $45{ }^{\circ} \mathrm{C}$ (circles), $55{ }^{\circ} \mathrm{C}$ (triangles), and $65^{\circ} \mathrm{C}$ (diamonds). 

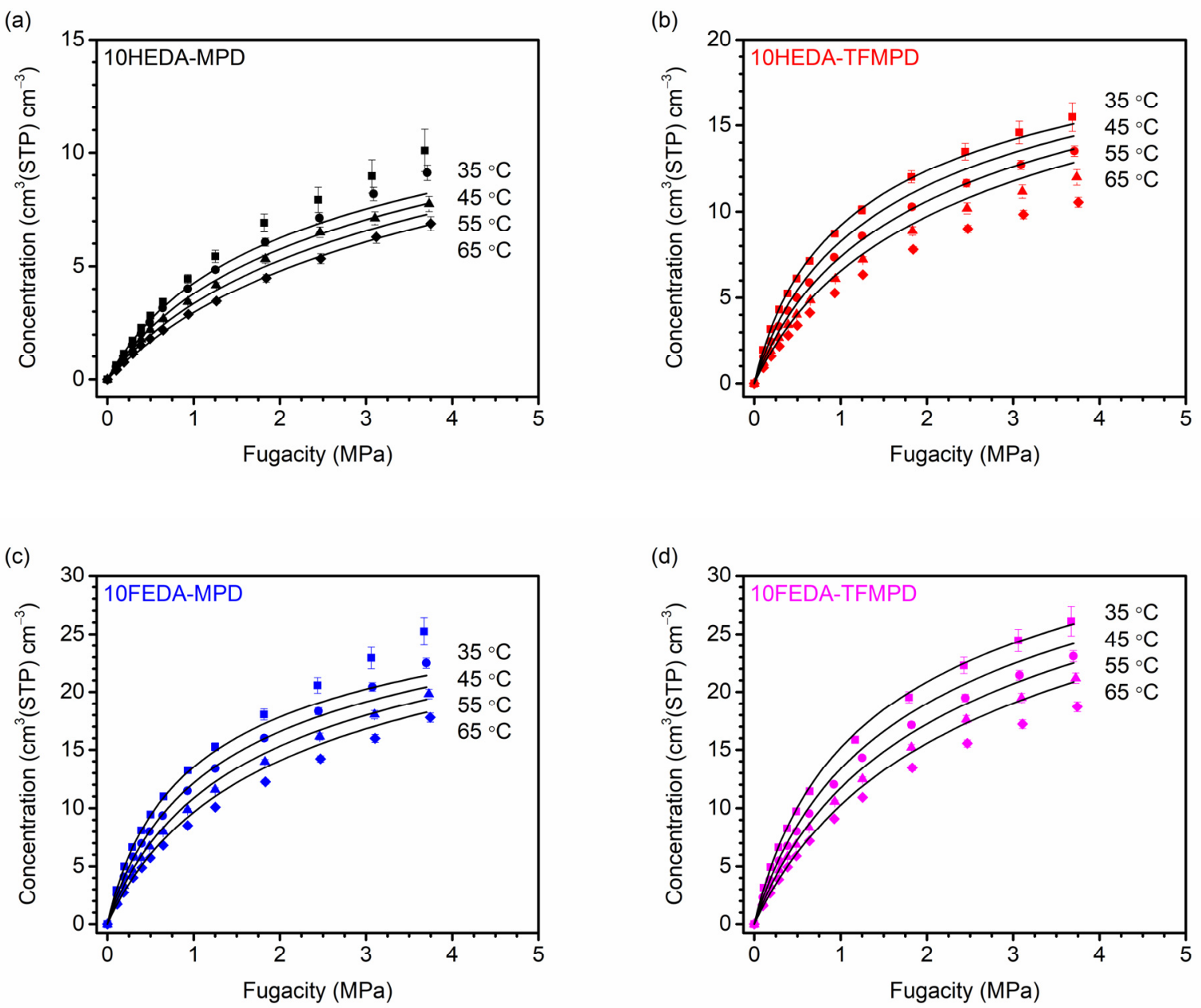

Figure S8: Isotherms for $\mathrm{CH}_{4}$ for the four polymers at $35{ }^{\circ} \mathrm{C}$ (squares), $45{ }^{\circ} \mathrm{C}$ (circles), $55{ }^{\circ} \mathrm{C}$ (triangles), and $65^{\circ} \mathrm{C}$ (diamonds). 

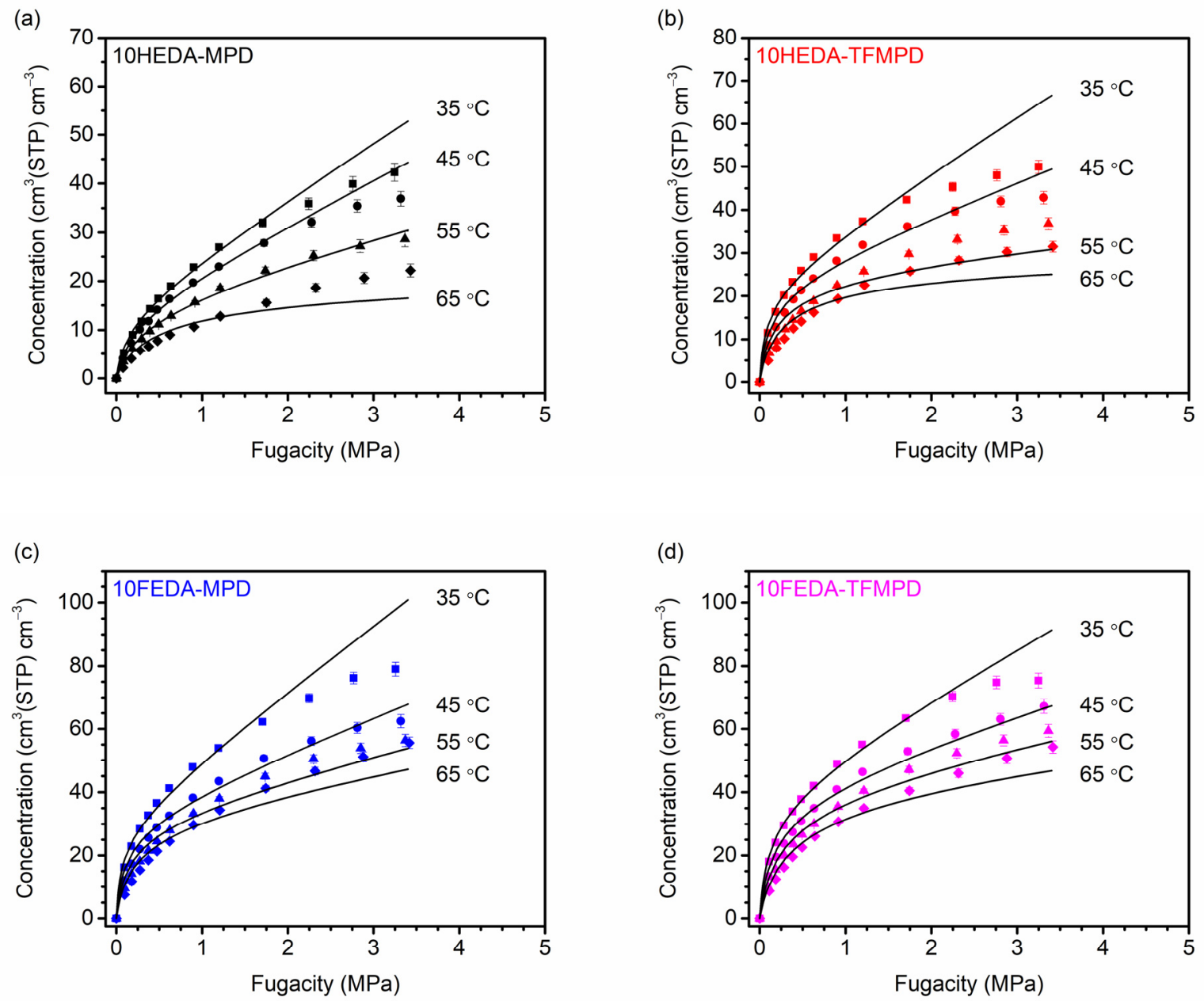

Figure S9: Isotherms for $\mathrm{CO}_{2}$ for the four polymers at $35{ }^{\circ} \mathrm{C}$ (squares), $45{ }^{\circ} \mathrm{C}$ (circles), $55{ }^{\circ} \mathrm{C}$ (triangles), and $65^{\circ} \mathrm{C}$ (diamonds). 

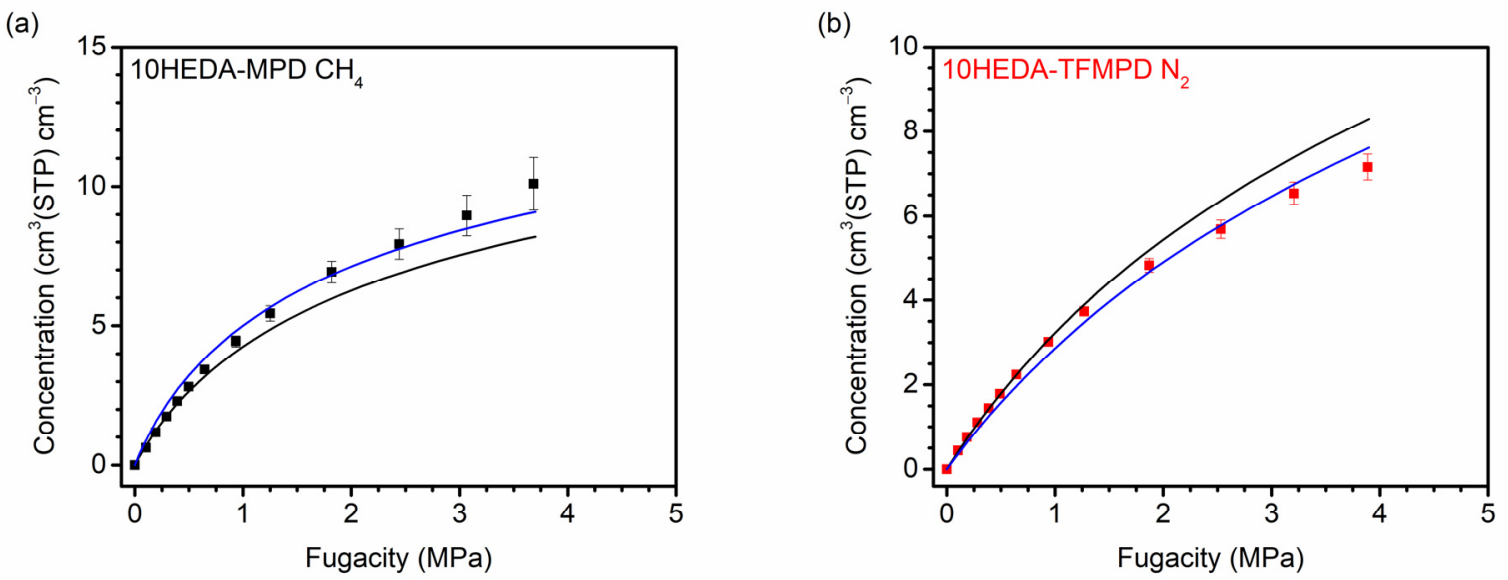

Figure S10: Comparison of the $\chi^{2}$ (black lines) and sum of squared residuals (blue lines) objective functions to fit the $k_{12}$ parameter. (a) $\mathrm{CH}_{4}$ in 10HEDA-MPD at $35{ }^{\circ} \mathrm{C}$. The best-fit $k_{12}$ changes from -0.024 to -0.052 and the fit at the low pressure region is over-predicted while the fit is improved in the high pressure region. (b) $\mathrm{N}_{2}$ in 10HEDA-TFMPD at $35^{\circ} \mathrm{C}$. The best-fit $k_{12}$ changes from -0.018 to 0.003 and the fit at the low pressure region is under-predicted while the fit is improved in the high pressure region. 
Table S7: Best-fit $k_{12}$ values fit to the sorption isotherm data at $35^{\circ} \mathrm{C}$. For $\mathrm{CO}_{2}$, this value was fit to points below $0.3 \mathrm{MPa}$.

\begin{tabular}{|l|l|l|l|l|}
\hline & $\mathrm{O}_{2}$ & $\mathrm{~N}_{2}$ & $\mathrm{CH}_{4}$ & $\mathrm{CO}_{2}$ \\
\hline 10HEDA-MPD & $0.006 \pm 0.004$ & $-0.021 \pm 0.006$ & $-0.024 \pm 0.003$ & $-0.064 \pm 0.003$ \\
10HEDA- & $0.016 \pm 0.002$ & $-0.018 \pm 0.003$ & $-0.023 \pm 0.001$ & $-0.078 \pm 0.001$ \\
\hline 10FEDD & & & & \\
\hline $\begin{array}{l}\text { 10FEDA- } \\
\text { TFMPD }\end{array}$ & $0.022 \pm 0.002$ & $-0.005 \pm 0.002$ & $0.035 \pm 0.001$ & $-0.055 \pm 0.001$ \\
\hline
\end{tabular}

Table S8: Best-fit $k_{s w}$ values $\left(\mathrm{MPa}^{-1}\right)$ for $\mathrm{CO}_{2}$ fit to the sorption data above $0.3 \mathrm{MPa}$.

\begin{tabular}{|l|l|l|l|l|}
\hline & $35{ }^{\circ} \mathrm{C}$ & $45^{\circ} \mathrm{C}$ & $55^{\circ} \mathrm{C}$ & $65^{\circ} \mathrm{C}$ \\
\hline 10HEDA-MPD & $0.018 \pm 0.005$ & $0.014 \pm 0.005$ & $0.007 \pm 0.005$ & $0.000 \pm 0.004$ \\
\hline TFMPD & $0.020 \pm 0.005$ & $0.012 \pm 0.005$ & $0.003 \pm 0.005$ & $0.000 \pm 0.002$ \\
\hline 10FEDA-MPD & $0.034 \pm 0.001$ & $0.017 \pm 0.001$ & $0.011 \pm 0.001$ & $0.008 \pm 0.001$ \\
\hline $\begin{array}{l}\text { 10FEDA- } \\
\text { TFMPD }\end{array}$ & $0.026 \pm 0.002$ & $0.014 \pm 0.001$ & $0.009 \pm 0.002$ & $0.005 \pm 0.002$ \\
\hline
\end{tabular}


References:

(1) De Angelis, M. G.; Sarti, G. C.; Doghieri, F. NELF Model Prediction of the Infinite Dilution Gas Solubility in Glassy Polymers. J. Membr. Sci. 2007, 289 (1-2), 106-122. https://doi.org/10.1016/j.memsci.2006.11.044.

(2) Li, Y.; Yavari, M.; Baldanza, A.; Di Maio, E.; Okamoto, Y.; Lin, H.; Galizia, M. Volumetric Properties and Sorption Behavior of Perfluoropolymers with Dioxolane Pendant Rings. Ind. Eng. Chem. Res. 2020, 59 (12), 5276-5286. https://doi.org/10.1021/acs.iecr.9b03411.

(3) De Angelis, M. G.; Merkel, T. C.; Bondar, V. I.; Freeman, B. D.; Doghieri, F.; Sarti, G. C. Gas Sorption and Dilation in Poly(2,2-Bistrifluoromethyl-4,5-Difluoro-1,3-Dioxole-CoTetrafluoroethylene): Comparison of Experimental Data with Predictions of the Nonequilibrium Lactice Fluid Model. Macromolecules 2002, 35 (4), 1276-1288. https://doi.org/10.1021/ma0106090.

(4) Minelli, M.; Sarti, G. C. Gas Permeability in Glassy Polymers: A Thermodynamic Approach. Fluid Phase Equilib. 2016, 424, 44-51. https://doi.org/10.1016/j.fluid.2015.09.027.

(5) Scherillo, G.; Sanguigno, L.; Galizia, M.; Lavorgna, M.; Musto, P.; Mensitieri, G. NonEquilibrium Compressible Lattice Theories Accounting for Hydrogen Bonding Interactions: Modelling Water Sorption Thermodynamics in Fluorinated Polyimides.

Fluid Phase Equilib. 2012, 334, 166-188. https://doi.org/10.1016/j.fluid.2012.06.030.

(6) Galizia, M.; Stevens, K. A.; Smith, Z. P.; Paul, D. R.; Freeman, B. D. Nonequilibrium Lattice Fluid Modeling of Gas Solubility in HAB-6FDA Polyimide and Its Thermally 
Rearranged Analogues. Macromolecules 2016, 49 (22), 8768-8779.

https://doi.org/10.1021/acs.macromol.6b01479.

(7) Ando, S.; Matsuura, T.; Sasaki, S. Synthesis and Properties of Perfluorinated Polyimides. In Fluoropolymers 2: Properties; Plenum Press: New York, 1999; pp 277-303.

(8) Ando, S.; Matsuura, T.; Sasaki, S.; Yamamoto, F. Method for Preparing Aromatic Compounds. 6,048,986, 2000.

(9) Ando, S.; Matsuura, T.; Sasaki, S. Perfluorinated Polyimide Synthesis. Macromolecules 1992, 25 (21), 5858-5860. https://doi.org/10.1021/ma00047a045.

(10) Hougham, G.; Tesoro, G.; Shaw, J. Synthesis and Properties of Highly Fluorinated Polyimides. Macromolecules 1994, 27 (13), 3642-3649. https://doi.org/10.1021/ma00091a028.

(11) Wu, A. X.; Drayton, J. A.; Rodriguez, K. M.; Qian, Q.; Lin, S.; Smith, Z. P. Influence of Aliphatic and Aromatic Fluorine Groups on Gas Permeability and Morphology of Fluorinated Polyimide Films. Macromolecules 2020, 53 (13), 5085-5095. https://doi.org/10.1021/acs.macromol.0c01024.

(12) Wu, A. X.; Drayton, J. A.; Mizrahi Rodriguez, K.; Benedetti, F. M.; Qian, Q.; Lin, S.; Smith, Z. P. Elucidating the Role of Fluorine Content on Gas Sorption Properties of Fluorinated Polyimides. Macromolecules 2021, 54 (1), 22-34. https://doi.org/10.1021/acs.macromol.0c01746.

(13) Ando, S.; Matsuura, T. Substituent Shielding Parameters of Fluorine-19 NMR on Polyfluoroaromatic Compounds Dissolved in Dimethyl Sulphoxide-d6. Magn. Reson. 
Chem. 1995, 33 (8), 639-645. https://doi.org/10.1002/mrc.1260330805.

(14) Liu, Y.; Wang, R.; Chung, T. S. Chemical Cross-Linking Modification of Polyimide Membranes for Gas Separation. J. Membr. Sci. 2001, 189 (2), 231-239. https://doi.org/10.1016/S0376-7388(01)00415-X.

(15) Wu, A. X.; Lin, S.; Mizrahi Rodriguez, K.; Benedetti, F. M.; Joo, T.; Grosz, A. F.; Storme, K. R.; Roy, N.; Syar, D.; Smith, Z. P. Revisiting Group Contribution Theory for Estimating Fractional Free Volume of Microporous Polymer Membranes. J. Membr. Sci. 2021, 119526. in press 